\title{
Unprecedented trinuclear Fe" triazole-based complex exhibiting a concerted and complete sharp spin transition above room temperature.
}

\author{
Narsimhulu Pittala, ${ }^{a}$ Franck Thétiot, ${ }^{a}$ Catherine Charles, ${ }^{a}$ Smail Triki, ${ }^{{ }^{a}}$ Kamel Boukheddaden, ${ }^{b}$ \\ Guillaume Chastanet ${ }^{c}$ and Mathieu Marchivie. ${ }^{c}$
}

\begin{abstract}
We report triazole-based trinuclear complex as the first related example to date that displays a complete one-step first-order [HSHS-HS $] \leftrightarrow[$ LS-LS-LS] spin transition at $318 \mathrm{~K}$. The strong ferroelastic interactions, between the three metal centers, have been identified as the source of the concerted spin transition in this trinuclear complex.
\end{abstract}

Among the molecular switchable materials, the spin crossover (SCO) complexes are particularly of interest, notably because of their potential applications in the development of new generations of electronic devices such as memories, molecular sensors and displays. ${ }^{1}$ When the spin pairing energy is close to the splitting energy, ${ }^{1,2}$ a SCO transition between the high-spin (HS, $\left.S=2,{ }^{5} T_{2 \mathrm{~g}}\right)$ and low-spin $\left(L S, S=0,{ }^{1} A_{1 \mathrm{~g}}\right.$ ) states can be induced by different external solicitations such as temperature, pressure, magnetic field and/or light irradiation. ${ }^{2,3}$ To date, $\mathrm{Fe}(\mathrm{II})$ metal complexes involving [ $\left.\mathrm{FeN}_{6}\right]$ octahedron coordination spheres have been the most studied SCO compounds. Among the few examples exhibiting remarkable SCO behavior, the systems based on the 1,2,4triazole ligands still remain among the most promising materials for future applications in electronic devices since some of them, particularly the coordination 1D-polymers of general formula $\left[\mathrm{Fe}\left(\left(\mathrm{NH}_{2}-\mathrm{trz}\right)_{3}\right](\mathrm{X})_{2}\right.$ and $\left[\mathrm{Fe}(\mathrm{Htrz})_{2}(\mathrm{trz})\right](\mathrm{X})\left(\mathrm{NH}_{2}-\right.$ $\operatorname{trz}=4$-amino-1,2,4-triazole, $\mathrm{Htrz}=4-\mathrm{H}-1,2,4$-triazole, $\mathrm{X}^{-}=$ standard monoanions), display wide thermal hysteresis loops around room temperature. ${ }^{4}$ However, the current and longstanding challenge to obtain single crystals of such coordination polymers makes difficult to access structural data at the molecular and inter-molecular scales; the latter are essential to understand and fine tune their SCO properties by acting on their cooperativity. Alternatively, new trinuclear triazole-based complexes, involving similar triple triazole bridges, are currently extensively studied (Table S1, ESI +$)^{5-8}$ These polynuclear systems could assist the tunable modeling and design of the SCO characteristics of the 1D chain polymers. However, in all these complexes, only the central Fe(II) ion undergoes a SCO transition, while the two terminal ones, commonly coordinated to two or three water molecules (or other oxygenated species), stringently remain in the HS state. ${ }^{5-}$ 8 Thus, those trinuclear complexes can be viewed as mononuclear SCO complexes in which the single active center experiences similar environment to the one described for the 1D chain polymers. Besides deepening the minutiae of the local environment of the $\mathrm{Fe}(\mathrm{II})$ active center, the investigations of larger SCO molecular discrete complexes, such as "true" trinuclear systems with three active SCO Fe(II) centers, could be crucial to elucidate the origin of the striking cooperativity observed in the 1D systems. Distinctly, the chemical control of cooperative hysteretic SCO polynuclear or oligomeric architectures is also of particular interest for the integration of discrete or isolated units into molecular devices. ${ }^{1,9}$ In this context, we have extended this polynuclear approach to atypical combinations of new functionalized triazole ligands (Scheme 1a), and cyanocarbanions (Scheme 1b) which can act as co-ligands through their $\mathrm{N}$-donor nitrile groups.

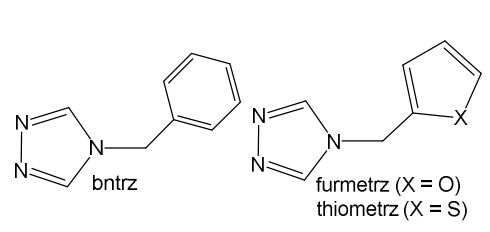

(a)

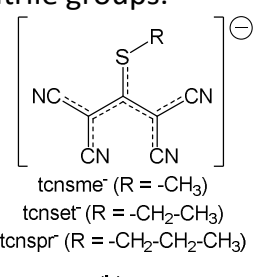

(b)
Scheme 1 Examples of 1,2,4-triazole (a) and cyanocarbanions (b) ligands.

The present work reports the synthesis and full structural and magnetic characterizations of the first example of triazole-based SCO Fe" trinuclear complex $\left[\mathrm{Fe}_{3}(\text { bntrz })_{6}(\text { tonset })_{6}\right]$ (1) exhibiting a complete and one-step spin transition above room temperature.

Single crystals of $\mathbf{1}$ have been synthesized using diffusion technique in fine glass tube $(3.0 \mathrm{~mm}$ diameter $)$ by layering methanolic solution of the bntrz ligand onto aqueous solution containing $\mathrm{K}$ (tcnset) and $\mathrm{Fe}\left(\mathrm{BF}_{4}\right)_{2} \cdot 6 \mathrm{H}_{2} \mathrm{O}$ salts (see Experimental section and Figs S1-S7, ESIt). ${ }^{10-11}$ Compound 1 has been structurally characterized at $360 \mathrm{~K}$ (HS state, colorless crystal), $250 \mathrm{~K}$ ( $L S$ state, pink crystal), and around the transition region (280-345 K) (Tables S2-S3). The magnetic susceptibility $\left(\chi_{m}\right)$ for 1 was measured over the 2-300 $\mathrm{K}$ temperature $(T)$ range on a set of single crystals sample. The thermal variation of the $\chi_{m} T$ product is displayed in Fig. 1 . At $380 \mathrm{~K}$, the $\chi_{m} T$ value $(9.48$ $\left.\mathrm{cm}^{3} \cdot \mathrm{K} \bullet \mathrm{mol}^{-1}\right)$ is consistent with three isolated HS (S = 2) hexacoordinated $\mathrm{Fe}(\mathrm{II})$ ions. Upon cooling, the $\chi_{m} T$ product decreases gradually down to a temperature value of $c a .320 \mathrm{~K}$. Below this temperature, it sharply decreases to a minimum value of $c a .0 .0 \mathrm{~cm}^{3} \cdot \mathrm{K} \cdot \mathrm{mol}^{-1}$, which is reached around $c a .250$ $\mathrm{K}$, indicating the presence of a sharp and complete $H S$ to $L S$ SCO first-order phase transition at $318 \mathrm{~K}$. Upon warming and cooling at a scan rate of $0.7 \mathrm{~K} / \mathrm{min}$ in settle mode, no thermal hysteresis effects were detected. Irradiation at $10 \mathrm{~K}$ did not reveal LIESST effects. The DSC study for $\mathbf{1}$, performed in the temperature range $290-340 \mathrm{~K}$ with a temperature scan rate of 
$2 \mathrm{~K} / \mathrm{mn}$, shows exo- and endo-thermic transitions with maxima at 317.5 and $318.7 \mathrm{~K}$, respectively (Inset Fig. 1). The small difference between DSC peak positions is most likely due to a kinetic effect. This phase transition occurs with an enthalpy

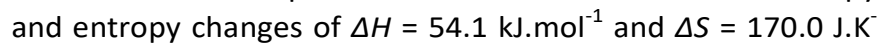
${ }^{1} . \mathrm{mol}^{-1}$, respectively. These values are in the range of those reported in the literature for similar SCO compounds. ${ }^{12}$

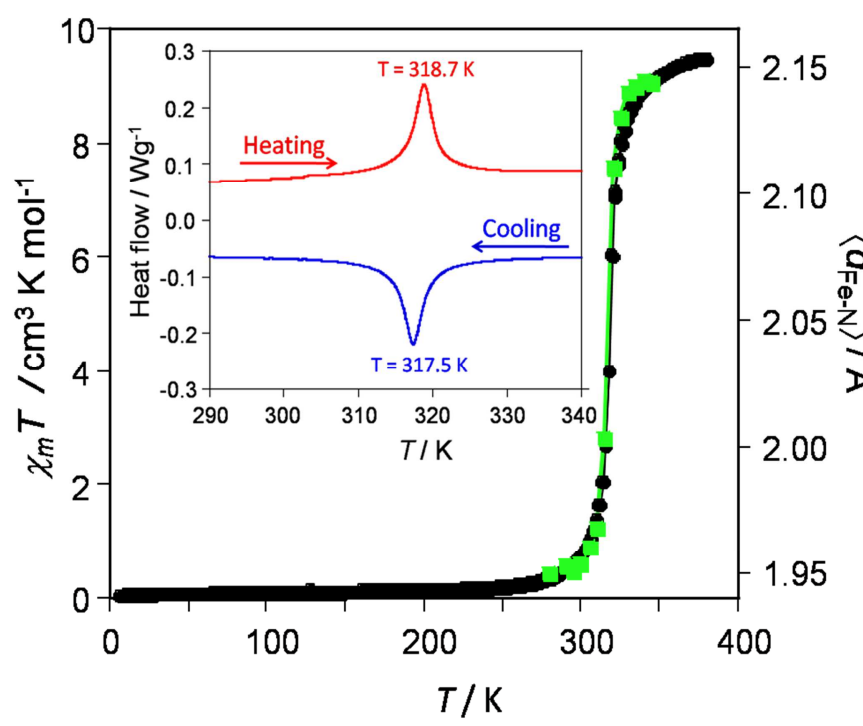

Fig. 1 Thermal evolutions of the $\chi_{m} T$ product $(\bullet)$, and the average Fe- $\mathrm{N}$ distances $(\square)$ around the transition region for $\mathbf{1}$. Inset: DSC study for $\mathbf{1}$ showing the exo- and endo-thermic transitions.

Table 1 Average Fe-N distances $\left(\left\langle d_{\mathrm{Fe}-\mathrm{N}}\right\rangle\right)$ and distortion parameters

\begin{tabular}{l|c|c|c|c|}
$T(\mathrm{~K})$ & \multicolumn{2}{|c|}{250} & \multicolumn{2}{c|}{360} \\
\hline${ }^{*}$ Fe" & Fe1 & Fe2 & Fe1 & Fe2 \\
center & & & & \\
\hline Fe1-N1 & $1.979(2)$ & & $2.175(2)$ & \\
Fe2-N2 & & $1.959(2)$ & & $2.170(2)$ \\
Fe2-N4 & & $1.940(2)$ & & $2.146(3)$ \\
\hline$\left\langle d_{\text {Fe-N }}\right\rangle(\AA)$ & $1.979(2)$ & $1.949(3)$ & $2.175(2)$ & $2.158(3)$ \\
$\Sigma / \Theta\left({ }^{\circ}\right)^{13}$ & $4(1) / 5(2)$ & $8(1) / 14(2)$ & $8(1) / 9(2)$ & $24(1) / 39(2)$ \\
\hline Spin state & $L S$ & $L S$ & $H S$ & $H S$ \\
\hline
\end{tabular}

*The two Fe(II) environments are defined by $\mathrm{N} 1$ ([Fe1(N1) $]$ ) and by N2 and $\mathrm{N} 4\left(\left[\mathrm{Fe} 2(\mathrm{~N} 2)_{3}(\mathrm{~N} 4)_{3}\right]\right)$ nitrogen atoms.

Based on the magnetic observations, the crystal structure of 1 has been determined at $360 \mathrm{~K}$ and $250 \mathrm{~K}$ (see Table S2, $\mathrm{ESI}+$ ). Selected Fe-N bond lengths and $\mathrm{N}-\mathrm{Fe}-\mathrm{N}$ bond angles at $360 \mathrm{~K}$ and $250 \mathrm{~K}$ are gathered in Table S3. Average Fe- N distances and distortion parameters for both metal centers (Fe1 and Fe2) are listed in Table 1 for the two spin states. The structure of $\mathbf{1}$ is built from two crystallographically inequivalent $\mathrm{Fe}(\mathrm{II})$ ions (Fe1 and $\mathrm{Fe} 2$ ), located respectively on $(1 / 32 / 31 / 6)$ and $(1 / 32 / 3 \mathrm{z})$ special positions, and one bntrz molecule and one (tcnset) anion, both located on general positions. The molecular structure of 1 consists of a neutral trinuclear complex of formula $\left.\left[\mathrm{Fe}_{3}(\text { bntrz })_{6} \text { (tcnset }\right)_{6}\right]$ which can be viewed as a [Fe2(bntrz $\left.)_{3} \mathrm{Fe} 1(\text { bntrz })_{3} \mathrm{Fe} 2\right]$ linear and centrosymmetric fragment in which the central metal ion (Fe1) is bound on both sides to two other $\mathrm{Fe}(\mathrm{II})$ centers (Fe2) through three $\mu_{2}$-bridging bntrz ligands (Fig. 2). The central metal ion (Fe1) is surrounded by six nitrogen atoms from six equivalent $\mu_{2}$-bntrz ligands, while each external Fe2 ion adopts $\mathrm{FeN}_{3} \mathrm{~N}_{3}$ octahedral environments arising from three equivalent bridging bntrz ligands and three unidentate (tcnset) anions (Fig. 2).

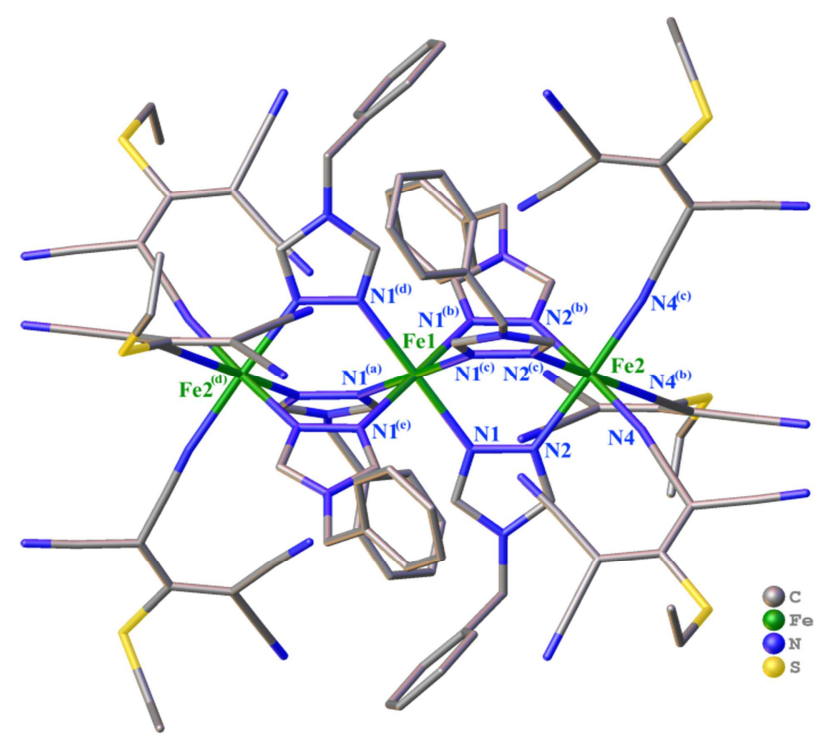

Fig. 2 View of the centrosymmetric trinuclear complex in 1 at $360 \mathrm{~K}$. (a): $2 / 3$ $y+x, 1 / 3+x, 1 / 3-z$; (b): 1-y, 1+x-y, z; (c): y-x, 1-x, z; (d): 2/3-x, 4/3-y, 1/3-z; (e): $-1 / 3+y, 1 / 3-x+y, 1 / 3-z$.

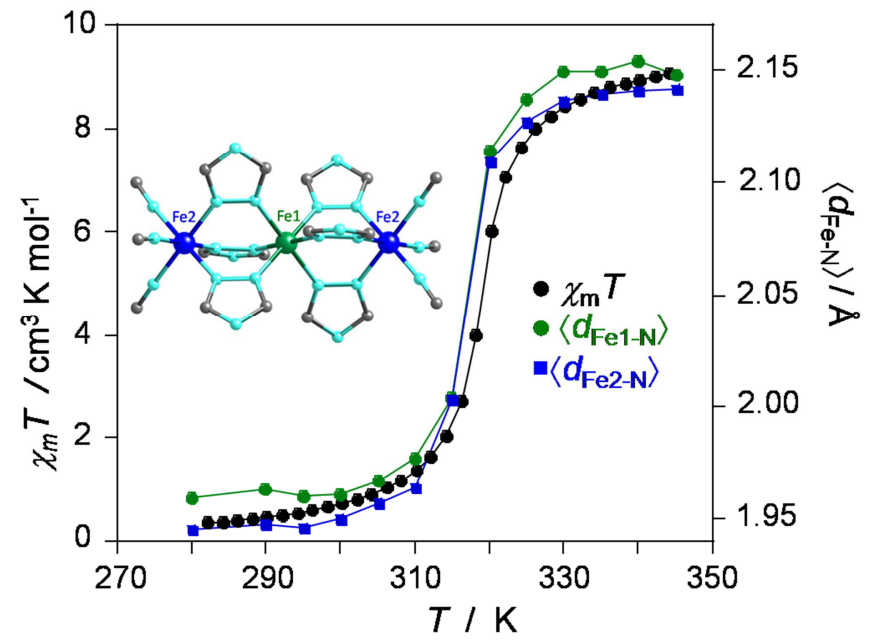

Fig. 3 Thermal evolutions of the average Fe- $\mathrm{N}$ distances of each Fe(II) center (Fe1 and $\mathrm{Fe} 2$ ) in the trinuclear units of 1 ([Fe2-Fe1-Fe2]), and of the $\chi_{m} T$ product in the $280-345 \mathrm{~K}$ range.

Examination of the Fe- $\mathrm{N}$ bonds and the $\mathrm{N}-\mathrm{Fe}-\mathrm{N}$ bond angles, for both $\mathrm{Fe}^{\prime \prime}$ environments ( $\mathrm{Fe} 1$ and $\mathrm{Fe} 2$ ), reveals that the central $\mathrm{Fe} 1$ ion adopts a regular $\mathrm{FeN}_{6}$ octahedral geometry which is defined by six equivalent nitrogen atoms ([Fe1(N1) $]$ ); distinctly, the two equivalent external $\mathrm{Fe} 2$ centers, surrounded by two different nitrogen atoms $\left(\left[\mathrm{Fe} 2(\mathrm{~N} 2)_{3}(\mathrm{~N} 4)_{3}\right]\right)$, display a more distorted octahedron geometry, as demonstrated by the values of $\Sigma$ and $\Theta$ parameters (Table 1$).{ }^{13}$ The average values of the Fe- $\mathrm{N}$ distances at $360 \mathrm{~K}\left(\mathrm{~d}_{\mathrm{Fe} 1-\mathrm{N}}=2.175(2) \AA\right.$ and $\left\langle\mathrm{d}_{\mathrm{Fe} 2-\mathrm{N}}\right\rangle=$ 
$2.158(3) \AA)$ and $250 \mathrm{~K}\left(\mathrm{~d}_{\mathrm{Fe} 1-\mathrm{N}}=1.979(2)\right.$ and $\left\langle\mathrm{d}_{\mathrm{Fe} 2-\mathrm{N}}\right\rangle=1.940(2)$ $\AA ̊)$ are in agreement with the presence of full HS and LS states, respectively. This observation is consistent with the presence of a complete [HS-HS-HS] $\leftrightarrow$ [LS-LS-LS] SCO transition, as initially revealed by the magnetic data (see Fig. 1).

The most intriguing and atypical feature of the present SCO compound 1 concerns the occurrence of a one-step transition despite the existence of two chemically different metal centers in the trimer (Fe2-Fe1-Fe2), as revealed by the crystallographic data in the two spin states. Thus, in order to undoubtedly confirm the absence of a two-step (or multi-step) transition, and to further understand the evolution of each $\mathrm{Fe}$ (II) environment (Fe1 and $\mathrm{Fe} 2$ ) during the transition, the crystal structure of 1 has been solved every $5 \mathrm{~K}$ around the transition region, i.e. between $280 \mathrm{~K}$ and $345 \mathrm{~K}$ (see CCDC numbers 1500728-1500740, ESI+). Thus, it must be noted that these additional structural investigations have not revealed any change of symmetry on the whole temperature range, while they have shown that the thermal evolution of the average Fe$\mathrm{N}$ distances $\left(\left\langle d_{\mathrm{Fe}-\mathrm{N}}\right\rangle\right)$ matches excellently the magnetic data (see Fig. 1). Moreover, the respective thermal behavior of Fe- $\mathrm{N}$ distances for the two Fe" centers almost perfectly overlap the thermal magnetic behavior (see Fig. 3). This appraisal suggests that both iron centers (Fe1 and Fe2) of the trinuclear complex, although displaying different crystallographic environments, undergo the spin transition in a concerted way, which is consistent with the one-step transition scenario from [LS-LSLS] to [HS-HS-HS] states.

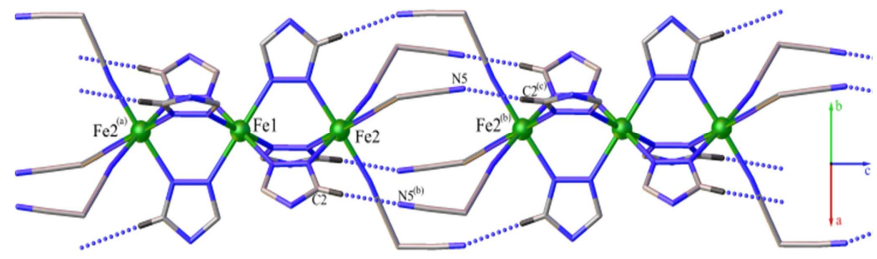

Fig. 4 View of 1 along the direction axis showing the hydrogen bond contacts between trinuclear units: C2...N5 = 3.329 (4) $\AA$ at $360 \mathrm{~K} ; \mathrm{C} 2 . . . \mathrm{N} 5=3.349$ (3) $\AA$ at 250 K. (a) $=2 / 3-x, 4 / 3-y, 1 / 3-z$; (b) $2 / 3-y+x, 1 / 3+x, 4 / 3-z$; (c) $-1 / 3+y, 1 / 3-$ $x+y, 4 / 3-z$.

The careful examination of the shortest inter-molecular contacts ( $\pi$ stacking, hydrogen bonding and van der Waals contacts) in $\mathbf{1}$ reveals that the trinuclear moieties are linked together by six hydrogen bonds involving the triazole ring and the $\mathrm{CN}$ branches from the cyanocarbanions of adjacent trinuclear complexes. Such inter-trinuclear contacts lead to a supramolecular chain oriented along the $c$ axis (Fig. 4). The corresponding chains are connected to each other through van der Waals contacts involving the S-Et groups of the cyanocarbanions and by weak interactions involving the $\pi$ system of benzyl moieties (centroid-centroid distances $=4.26$ $\AA$ at $250 \mathrm{~K} ;$ Fig. S8). During the LS to HS transition, the intratrinuclear Fe1-Fe2 distances increase from 3.657(1) $\AA(250 \mathrm{~K})$ to $3.865(1) \AA(360 \mathrm{~K})$; conversely, the inter-trinuclear $\left[\mathrm{Fe} 2 \cdots \mathrm{Fe} 2^{(\mathrm{b})}\right.$ ] distances decrease from 7.419(1) $\AA$ (250 K) to 7.094(1) $\AA$ (360 K), as depicted in Figs. S9-S10. Nevertheless, it is noteworthy that the corresponding molecular separation along the $c$ axis varies little upon the transition, as the distances between trinuclear centroids slightly increase from $14.734(2) \AA(250 \mathrm{~K})$ to $14.824(2) \AA(360 \mathrm{~K})$.
This antagonistic co-evolution of the intra- and inter-trinuclear distances implies that the anisotropic change of the SCO is accompanied by a structural rearrangement involving both the cyanocarbanions and the side chains of the triazoles, as evidenced by the very weak modifications of the $\mathrm{H}$-bonds between $250 \mathrm{~K}$ and $360 \mathrm{~K}$. Thus, this rearrangement keeps the inter-trimer interactions very similar in both spin states. This observation further confirms the strong links connecting the trinuclear units along the $c$ direction, which prevents the absorption of the total intratrinuclear Fe1-Fe2 deformation. As a result, the metal centers (Fe1 and $\mathrm{Fe} 2$ ) of the trimers slightly move away from each other (along the $c$ axis) upon LS to HS conversion. In the other directions ( $a$ and $b$ ), the evolution of the inter-chain distances during the LS to HS transition follows a more expected behavior, with an increase from $14.664(1) \AA$ at $250 \mathrm{~K}$ to 15.043 (1) $\AA$ at $360 \mathrm{~K}$; the same applies to the molecular volume and the thermal expansion, which is the signature of weaker interactions within the $a b$ plane. These thermal structural evolutions clearly indicate the existence of a strong $1 \mathrm{D}$ character of the crystal along the [001] direction which dominates the system's behavior. This one-dimensional structural feature constitutes a unique specimen within the trinuclear SCO systems available in the literature. . $^{5}$

We have prepared and fully characterized a new trinuclear $\left[\mathrm{Fe}_{3}(\text { bntrz })_{6}(\text { tcnset })_{6}\right]$ (1) neutral complex that exhibits a complete and sharp one-step spin transition above room temperature $\left(T_{1 / 2}=\right.$ $318 \mathrm{~K})$, and defined to our best knowledge as the first SCO trinuclear complex exhibiting such a complete spin transition. The one-step nature of the magnetic transition has been notably confirmed by DSC measurements and detailed structural studies around the transition region that clearly demonstrated that the thermal evolutions for the three Fe" environments are similar and fit adequately the one-step transition from [LS-LS-LS] to [HS-HS-HS] states. This unprecedented behavior has been mainly assigned to the presence of a rigid elastic interaction between the central metal ion and its neighbours within the trimer. Yet the inter-trimer interaction along the supramolecular chain is also significant, as proven by the observed smallest variation of the corresponding lattice parameter $c(\Delta a / a$ upon the transition is 4 times greater than $\Delta c / c$ ); the latter involves not only $\mathrm{Fe} 2 \cdots \mathrm{Fe} 2$ distance change (from 7.419 (1) $\AA$ at250 K to 7.094(1) $\AA$ at $360 \mathrm{~K}$ ) but also that of Fe1-Fe2 sites (from 3.657(1) $\AA$ at $250 \mathrm{~K}$ to $3.865(1) \AA$ at $360 \mathrm{~K}$ ). Besides, although the two $\mathrm{Fe}(\mathrm{II})$ centers display different environments and related ligand fields within the trimer, their transition takes place concomitantly due to the strong ferro-elastic coupling linking the two iron centers. Indeed, the LS-HS-LS or HS-LS-HS configurations in the present case are very high in energy, due to the excess of elastic stress which cannot be accommodated within the trimer, which then excludes the occurrence of a two-step transition. Referring to the cooperative character of the transition, it is mostly due to the interactions within the chains (strong intra- and weak inter-trimers coupling), thus explaining the absence of a thermal hysteresis at the transition. The rigid nature of the trimer and its rather high transition temperature support the argument that the transition of either the central or the external metal ions drives the whole cluster, which basically behaves as a strongly correlated entity. In summary, this study opens the way to a rich family of discrete SCO polynuclear complexes by tuning the rigidity of the anions, and the present derivative constitutes an excellent model system for 
theoretical investigations using elastic models ${ }^{14}$ in order to disentangle the contributions of intra- and inter-molecular elastic interactions and to clarify how from their competing character at the microscopic level emerges the two- or one-step transitions at the macroscopic scale.

\section{Acknowledgements}

We thank the CNRS, the Universities of Brest (UBO), Versailles (Paris-Saclay) and Bordeaux, the "Agence Nationale de la Recherche" (ANR-12-BS07-0030-01) and the European community (FP7 project: PCIG-GA-2011-304193 NANOCOORD).

\section{Notes and references}

1 E. Coronado, J.R. Galán-Mascarós, M. Monrabal-Capilla, J. García-Martínez and P. Pardo-lbáñez, Adv. Mater., 2007, 19, 1359; A. Bousseksou, G. Molnar, L. Salmon and W. Nicolazzi, Chem. Soc. Rev., 2011, 40, 3313; G. Félix, K. Abdul-Kader, T. Mahfoud, I. A. Gural'skiy, W. Nicolazzi, L. Salmon, G. Molnar and A. Bousseksou, J. Am. Chem. Soc., 2011, 133, 15342. J. Linares, E. Codjovi and Y. Garcia, Sensors, 2012, 12, 4479.

2 P. Gütlich, A-B. Gaspar and Y. Garcia, Beilstein J. Org. Chem., 2013, 9, 342; M. Shatruk, H. Phan, B. A. Chrisostomo and A. Suleimenova, Coord. Chem. Rev., 2015, 289-290, 62; C. Atmani, F. El Hajj, S. Benmansour, M. Marchivie, S. Triki, F. Conan, V. Patinec, H. Handel, G. Dupouy and C. J. Gómez-García, Coord. Chem. Rev., 2010, 254, 1559.

3 Y. Garcia, V. Niel, M. C. Muñoz and J.-A. Real, Top. Curr. Chem., 2004, 233, 229; S. Hayami, R. Moriyama, Y. Shigeyoshi, R. Kawajiri, T. Mitani, M. Akita, K. Inoue and Y. Maeda, Inorg. Chem., 2005, 44, 7295; R. Ishikawa, K. Matsumoto, K. Onishi, T. Kubo, A. Fuyuhiro, S. Hayami, K. Inoue, S. Kaizaki and S. Kawata, Chem. Lett., 2009, 38, 620; G. Morgan, K. D. Murnaghan, H. Muller-Bunz, V. McKee and C. J. Harding, Angew. Chem. Int. Ed., 2006, 45, 7192; M. A. Halcrow, Chem. Soc. Rev., 2011, 40, 4119; P. Guionneau, Dalton Trans., 2014, 43, 382.

4 J.G. Haasnoot, Coord. Chem. Rev., 2000, 200-201, 131; 0. Roubeau, Chem. Eur. J., 2012, 18, 15230.

5 L. Antolini, A. C. Fabretti, D. Gatteschi and R. Sessoli, Inorg. Chem., 1990, 29, 143; Y. M. Klein, N. F. Sciortino, C. E. Housecroft, C. J. Kepert and S. M. Neville, Magnetochemistry, 2016, 2, 7.

6 O. G. Shakirova, L. G. Lavrenova, Y. G. Shvedenkov, G. A. Berezovskii, D. Y. Naumanov, L. A. Sheludyakova, G. V. Dolgushin and S. V. Larionov, Russ. J. Coord. Chem., 2004, 30, 473; M. Thomann, O. Kahn, J. Guilhem and F. Varret, Inorg. Chem., 1994, 33, 6029.

7 H. Z. Scott, T. M. Ross, B. Moubaraki, K. S. Murray and S. M. Neville, Eur. J. Inorg. Chem., 2013, 803; Y. Garcia, P. Guionneau, G. Bravic, D. Chasseau, J. A. K. Howard, O. Kahn, V. Ksenofontov, S. Reiman and P. Gütlich, Eur. J. Inorg. Chem., 2000, 1531; G. Vos, R. A. Le Febre, R. A. G. de Graaff, J. G. Haasnoot and J. Reedijk, J. Am. Chem. Soc., 1983, 105, 1682; J. J. A. Kolnaar, G. van Dijk, H. Koojiman, A. L. Spek, V. Ksenofontov, P. Gütlich, J. G. Haasnoot and J. Reedijk, Inorg. Chem., 1997, 36, 2433; D. Savard, C. Cook, G. D. Enright, I. Korobkov, T. J. Burchell and M. Murugesu, CrystEngComm., 2011, 13, 5190.
8 V. Gómez, J. Benet-Buchholz, E. Martin and J. R. GalanMáscarós, Chem. Eur. J., 2014, 20, 5369; V. Gómez, C. S. de Pipaón, P. Maldonado-Illescas, J. C. Waerenborgh, E. Martin, J. Benet-Buchholz and J. R. Galan-Máscarós, J. Am. Chem. Soc., 2015, 137, 11924.

9 C. Lefter, S. Rat, J. S. Costa, M. D. Manrique-Juárez, C. M. Quintero, L. Salmon, I. Séguy, T. Leichle, L. Nicu, P. Demont, A. Rotaru, G. Molnár and A. Bousseksou, Adv. Mater., 2016, 28, 7508.

10 H. O. Bayer, R. S. Cook and W. C. Von Mayer, US Patent, 1974, 3821376; N. Pittala, F. Thétiot, S. Triki, K. Boukheddaden, G. Chastanet and M. Marchivie, Chem. Mater., 2017, 29, 490.

11 S. Lethu and J. Dubois, Eur. J. Org. Chem., 2011, 3920; P. G. Baraldi, F. Fruttarolo, M. A. Tabrizi, D. Preti, R. Romagnoli, H. ElKashef, A. Moorman, K. Varani, S. Stefania Gessi, S. Merighi and P. A. Borea, J. Med. Chem., 2003, 46, 1229; G. Dupouy, M. Marchivie, S. Triki, J. Sala-Pala, J.-Y. Salaün, C. J. Gómez-García and P. Guionneau, Inorg. Chem., 2008, 47, 8921.

12 O. Roubeau, M. Castro, R. Burriel, J. G. Haasnoot and J. Reedijk, J. Phys. Chem. B, 2011, 115, 3003.

13 M. Marchivie, P. Guionneau, J.-F. Létard and D. Chasseau, Acta Cryst. B, 2005, B61, 25.

14 M. Paez-Espejo, M. Sy and K. Boukheddaden, J. Amer. Chem. Soc., 2016, 138, 3202. 